\title{
LAUDATIO DEL DR. CLAUDI ESTEVA: EL PAPER INSTITUCIONALITZADOR
}

\author{
Joan Prat Carós \\ Universitat Rovira i Virgili \\ joan.prat@urv.cat
}

Rector Magnífic, il.lustres autoritats acadèmiques, familiars del Dr. Esteva, col-legues, amigues i amics,"

Aquesta serà una laudatio a dues mans (o a dues veus), ja que la durem a terme dos deixebles de Claudi Esteva que pertanyem a dues generacions diferents. Jo mateix, que soc de la generació més vella, em centraré en els seus aspectes de docent i mestre, mentre que el Dr. Àngel Martínez, el copadrí més jove, emfasitzarà la seva figura com a investigador i pensador. Iniciaré aquest elogi de Claudi Esteva Fabregat -el Dr. Esteva, com sempre el vam anomenar els seus deixebles catalans- amb unes breus pinzellades biogràfiques.

\footnotetext{
* Aquest text es correspon a l'elogi del candidat realitzat pel doctor Joan Prat Carós en la Investidura com a doctor honoris causa a títol pòstum del doctor Claudi Esteva Fabregat. Sessió acadèmica extraordinària del 10 de novembre de 2017.
} 
El Dr. Esteva va néixer a Marsella l'any 1918, però es va criar al barri de Sants de Barcelona. Va participar a la Guerra Civil Espanyola de 1936 en el bàndol republicà, i la victòria franquista el va portar al camí de l'exili. Després d'una estada dura de cent dies en un camp de concentració del sud de França, es va embarcar (o el van embarcar) al vaixell Sinaia cap a Mèxic. Allí va sobreviure amb diverses activitats laborals, entre les quals destaca la de jugador i després entrenador de l'equip de futbol O'Farril de la ciutat de Puebla (Morelos).

Es va formar com a antropòleg a l'Escuela Nacional de Antropología e Historia de Mèxic, on el 1955 va obtenir el títol de Mestre en Ciències Antropològiques. Immediatament fou nomenat professor de Cultura i Personalitat i secretari d'un nucli psicoanalític dirigit per Erich Fromm, que llavors vivia a Mèxic convidat per un nucli de psiquiatres del país.

La tornada a Espanya es va produir l'any 1956, més concretament a Madrid, on el Dr. Esteva va trobar un panorama intellectual desolador. És un fet ben sabut que els règims feixistes no són amics de les ciències socials i la poca sociologia i antropologia tolerades pel franquisme estaven en mans d'eclesiàstics afins al nacionalcatolicisme. L'excepció era Julio Caro Baroja, historiador, arqueòleg i etnòleg-antropòleg, allunyat, però, del món universitari.

Amb la intenció d'accedir a la universitat espanyola, en un temps rècord va fer la llicenciatura i el doctorat al Departament d'Història d'Amèrica de la Universidad Complutense de Madrid, en el qual va ser durant uns anys professor encarregat de curs amb un sou misèrrim.

Casat i amb criatures, va sobreviure a Madrid fent enquestes per als ministeris, redactant informes, que implicaven treball de camp a Sayago (província de Zamora) o entre els fang i els bubis, ètnies de l'antiga colònia africana de la Guinea espanyola. El informes eren lliurats a organismes oficials. Lany 1965 fou nomenat director del Museu Nacional d'Etnologia de Madrid, en substitució de Caro Baroja, perquè havia dimitit del càrrec, que d'altra banda no comportava cap mena de retribució econòmica.

Allí va fundar l'Escuela de Estudios Antropológicos, la primera institució d'antropologia cultural pròpiament dita que mai havia existit a l'Estat espanyol. El pla d'estudis estava inspirat en el model mexicà, que 
al seu torn seguia els patrons del nord-americà hegemònic en aquell moment. Així, els estudiants rebien formació teòrica en quatre grans branques - antropologia física, arqueologia, lingüística i etnologia-, a més d'unes pràctiques intensives de treball de camp realitzades durant l'estiu a l'Alt Aragó. Aquests alumnes diplomats a l'Escola de Estudis Antropològics foren després els primers catedràtics d'Antropologia a les universitats de Madrid i Sevilla i poc menys a la de Barcelona.

Malgrat l'èxit de l'Escola, basat en la professionalitat i carisma del Dr. Esteva, l'any 1968 es convocava una plaça de professor agregat a la Universitat de Barcelona (recordeu que l'agregat era el pas previ de la càtedra), que ell guanyà, i tot seguit es va traslladar amb la família cap a la ciutat comtal. Aquest serà el moment que la gent de la meva generació —els que voregem els setanta anys per dalt o per baix-el vam conèixer.

En efecte, recordo que quan estava a quart curs de carrera -especialitat Filosofia - alguns companys, entre els quals Joan Frigolé i Jesús Contreras, em van parlar d'un nou professor que acabava d'arribar de Madrid i feia una assignatura nova, Introducció a l'Antropologia Cultural, i que gràcies al recent estrenat pla Maluquer ens hi podíem matricular sense problema.

Així ho vaig fer, i al cap d'unes poques classes impartides a les vuit del matí en una Aula Magna plena de gom a gom, vaig tenir la certesa absoluta que allò era el meu fort i jo també volia ser antropòleg. Un deixeble seu de Madrid, el catedràtic Manuel Gutiérrez Estévez, i el colllega Josep Maria Comelles han descrit l'impacte que ens van causar les classes del Dr. Esteva. El primer ho va relatar amb aquestes paraules:

Fue mi primer profesor de antropología, y recordaré siempre con extraordinario afecto y simpatía la capacidad que tenía para hacernos imaginar sitios muy lejanos. Empezaba a hablar de los indios de las praderas, y todos teníamos la sensación de estar allí. No solamente de estar allí, sino de estar entonces, cuando había indios [...]. Hablaba de tal forma que nos hacía sentir el temor de los hopi ante los ataques de los comanches; nos daba una visión muy plástica, que no solo excitaba nuestra imaginación juvenil sino que nos estimulaba hacia la teoría. (AIBR, 2003, núm. 29) 
El segon, el Dr. Comelles, també es refereix a la «ensoñación comanche» explicada pel Dr. Esteva com en cinemascope.

D'aquesta manera, doncs, descobríem l'antropologia de la mà ferma i del carisma del mestre. En efecte, la disciplina ens ajudava a mirar el món d'una manera diferent de l'habitual. D'entrada, representava una glopada d'aire fresc que obria les portes a la diversitat. Tot el que havíem estudiat fins aquell moment estava vinculat a la civilització occidental d'arrels grecoromanes i judeocristianes. L'antropologia, en canvi, ens brindava la possibilitat d'entendre les diverses cultures i civilitzacions que poblen la Terra. Semblantment, comprendre i assumir que els marges de pedra seca construïts pels pagesos del poble on havíem nascut eren cultura, i que no només ho era la «Simfonia del Nou Món» de Dvorak o la pintura del Greco, va ser en aquells moments un descobriment de primer ordre. També ens van causar un fort impacte un seguit de conceptes explicats amb passió per Claudi Esteva, per exemple, cultura, relativisme cultural, enculturació, etnocentrisme, socialització, ethos, visió del món, etc. Enfront dels fonamentalismes i dels dogmatismes d'aquella època, l'antropologia ens permetia acceptar i valorar positivament la diferència i fer nostre aquell principi elemental però sistemàticament conculcat que l'Home és un, però les maneres de ser home o dona són variades i múltiples.

Els primers deixebles del Dr. Esteva a Barcelona procedien de diferents especialitats. Per il.lustrar-ho podem recórrer a l'exemple dels cinc primers antropòlegs tarragonins: Joan Josep Pujadas, que venia de la lingüística; Dolors Comas d'Argemir, de la història antiga; Josep M. Comelles, de medicina i psicologia; Oriol Romaní, d'història de l'art, i jo mateix, que sóc el més vell del grup, de filosofia. Gairebé tots vam tenir beques FPI (formació de personal investigador) i vam passar a col-laborar en les tasques del Centre d'Etnologia Peninsular, del CSIC, institució de la qual s'havia fet càrrec el Dr. Esteva. Ell va esdevenir el nostre tutor, director de tesi i qui ens va introduir en el treball de camp a l'Alt Aragó, a la Garrotxa i, els més afortunats, al Perú, a Chinchero, un poble prop de Cusco. A diferència d'altres catedràtics del moment partidaris de l'ordeno y mando, el Dr. Esteva ens va deixar absoluta llibertat d'elecció en els nostres temes de tesi. 
D'aquesta manera, el seu padrinatge acadèmic va ser decisiu per al futur professional de molts de nosaltres.

A més a més de gaudir de les seves classes, en què, com dirien els nostres adolescents, el Dr. Esteva s'enrotllava més que bé, també ho feia fora de l'aula. I aquí continuo apel.lant als meus records personals.

Quan jo era el seu becari, l'espai que compartia amb la resta de companys era un petit cubicle a l'edifici de l'antiga Universitat, a la Gran Via de les Corts Catalanes. El Dr. Esteva treballava en una mena de golfes i els becaris, en un despatxet minúscul que hi havia a sota. Pels volts de tres quarts de dues o les dues del migdia, ell baixava per les escales i, si estàvem sols, preguntava:

-Què va a dinar, vostè, Joan?

-Doncs, sí, Dr. Esteva.

-I on va?

-A ca la Mari (o a ca la Trini, he oblidat el nom del lloc, però no que era el més baratet que la meva pobra butxaca es podia permetre).

-I què li costa?

-Cinquanta pessetes.

- Miri, jo vaig a cal Dario, que en costa setanta-cinc. Si vol, podem anar-hi junts i jo li pago la diferència.

Evidentment ens apuntàvem ràpidament a aquest molt bon tracte que ens permetia dinar millor pel mateix preu i, a més a més, gaudir de la conversa variadíssima del Dr. Esteva, un conversador incansable. A vegades comentava les notícies del dia, d'altres feia llargues explicacions sobre la seva estada i formació a Mèxic o bé detallava el contingut dels articles o llibres que estava escrivint. Els atacs furibunds contra els partidaris de l'antropologia social (era un ferm defensor de l'antropologia cultural) els combinava amb anècdotes divertides, ja que sempre el va acompanyar el sentit de la ironia —una ironia molt anglesa- que caracteritzava les seves intervencions orals més que no pas les escrites...

Una darrera reflexió per acabar. A les universitats hi ha centenars (o milers) de professors, però els mestres, els autèntics mestres, es troben amb comptagotes. Jo, per exemple, només en vaig tenir dos: el Dr. Emilio Lledó, a filosofia, i el Dr. Esteva, a antropologia. Però, què defineix un 
mestre? D'entrada, el rigor i la potència intellectual, la imaginació creadora, l'estímul per provocar en els altres lectures, pensaments i reflexions, però també la passió en la transmissió dels coneixements i aquesta estranya condició que podem anomenar carisma. El Dr. Claudi Esteva-Fabregat posseïa totes aquestes capacitats amb escreix. Certament els mestres són pocs, però tenen l'avantatge que no moren mai, o més ben dit, malgrat la seva desaparició física, com és el cas, continuen perdurant per sempre més en la nostra memòria i en el nostre record per la petjada immensa que hi van deixar. 